\title{
Genome-wide identification of the MADS- box transcription factor family in autotetraploid cultivated alfalfa (Medicago sativa L.) and expression analysis under abiotic stress
}

Xueming Dong, Hao Deng, Wenxue Ma, Qiang Zhou and Zhipeng Liu*

\begin{abstract}
Background: Alfalfa, the "queen of forage", is the most extensively cultivated forage legume in the world. The development and yield of alfalfa are seriously limited by abiotic stress. MADS-box transcription factors are one of the largest gene families and play a pivotal role in plant development and abiotic stress. However, little is known regarding the MADS-box transcription factors in autotetraploid cultivated alfalfa.

Results: In the present study, we identified 120 MsMADS-box genes in the alfalfa genome. Phylogenetic analysis indicated that 75 type-I MSMADS-box genes were classified into the Ma, M $\beta$, and My subgroups, and 45 type-II MSMADS-box genes were classified into 11 subgroups. The promoter region of MSMADS-box genes containing several hormone and stress related elements. Chromosomal location analysis revealed that 117 MsMADS-box genes were unevenly distributed on 32 chromosomes, and the remaining three genes were located on unmapped scaffolds. A total of nine pairs of segmental duplications and four groups of tandem duplications were found. Expression analysis showed that MSMADS-box genes were differentially expressed in various tissues and under abiotic stresses. qRT-PCR analysis revealed that the expression profiles of eight selected MsMADS-box genes were distinct under various stresses.

Conclusions: In this study, MSMADS-box genes were identified in the cultivated alfalfa genome based on autotetraploid level, and further confirmed by Gene Ontology (GO) analysis, phylogenetic analysis, sequence features and expression analysis. Taken together, these findings will provide clues for further study of MsMADS-box functions and alfalfa molecular breeding.

Our study is the first to systematically identify and characterize the MADS-box transcription factors in autotetraploid cultivated alfalfa (Medicago sativa L.), and eight MsMADS-box genes were significantly involved in response to various stresses.
\end{abstract}

Keywords: Abiotic stress, Autotetraploid, Cultivated alfalfa, Expression profiles, MADS-box genes, Transcription factor

\footnotetext{
* Correspondence: Izp@|zu.edu.cn

State Key Laboratory of Grassland Agro-ecosystems, Key Laboratory of Grassland Livestock Industry Innovation, Ministry of Agriculture and Rural Affairs, Engineering Research Center of Grassland Industry, Ministry of Education, College of Pastoral Agriculture Science and Technology, Lanzhou University, 730000 Lanzhou, People's Republic of China
}

C C The Author(s). 2021 Open Access This article is licensed under a Creative Commons Attribution 4.0 International License, which permits use, sharing, adaptation, distribution and reproduction in any medium or format, as long as you give appropriate credit to the original author(s) and the source, provide a link to the Creative Commons licence, and indicate if changes were made. The images or other third party material in this article are included in the article's Creative Commons. licence, unless indicated otherwise in a credit line to the material. If material is not included in the article's Creative Commons licence and your intended use is not permitted by statutory regulation or exceeds the permitted use, you will need to obtain permission directly from the copyright holder. To view a copy of this licence, visit http://creativecommons.org/licenses/by/4.0/ The Creative Commons Public Domain Dedication waiver (http://creativecommons.org/publicdomain/zero/1.0/) applies to the data made available in this article, unless otherwise stated in a credit line to the data. 


\section{Background}

Transcription factors (TFs) regulate gene expression at the transcriptional level and are involved extensively in plant growth and development, organ morphogenesis, stress and hormone signal responses [1]. The MADS-box gene family is one of the largest families of TFs and is widely distributed in eukaryotes. The word "MADS" was derived from the initials of four proteins: Mini Chromosome Maintenance 1(MCM1) of yeast [2], Agamous (AG) of Arabidopsis thaliana [3], Deficiens (DEF) of snapdragon [4], and Serum Response Factor (SRF) of humans [5]. According to evolutionary relationships, the MADSbox protein family is clustered into type-I and type-II groups, which might be derived from gene duplication events of the same ancestor [6]. Type-I MADS-box proteins typically contain a highly conserved SRF-like domain with one to two exons and can be further divided into three subgroups: $M \alpha, M \beta$, and $M \gamma$ [7]. Type-II $M A D S$-box genes are also called MIKC-type genes, which consist of two subgroups: MIKC ${ }^{*}$ and MIKC ${ }^{\mathrm{C}}$ [8]. According to differences in gene function and sequence homology, MIKC $\mathrm{C}^{\mathrm{C}}$-type genes are classified into 14 subgroups, which are defined as AG, SEP/AGL2, AGL6, AGL12, AGL15, AGL17, FLC, SQUA, TM3/SOC1, TM8, STMADS11, GGM13, and DEF/GLO [9]. Notably, $M A D S$-box genes belonging to the same subfamily often show analogous expression patterns and related functions $[10,11]$.

The MADS-box gene family plays not only a regulatory role in the development of flower organs but also important roles in controlling flowering time, determining the differentiation of meristematic tissue, controlling embryonic development, promoting root formation, and regulating the development of seeds and fruits [12, 13]. Recently, many studies have proven that $M A D S$-box genes play a significant role in the regulation of plant tolerance to extreme conditions, such as drought, salt, high temperature and cold stress $[14,15]$. In rice, knocking down the expression of OsMADS26 enhances the resistance of rice to drought and pathogenic bacterial stress [16, 17]. In wheat, overexpression of TaMADS, a type-II (MIKC) $M A D S$-box gene, results in early flowering through upregulation of LUMINIDEPENDENS (LD) and FLOWERING CONTROL LOCUS A (FCA) expression under cold treatment [18]. Similarly, overexpression of SIMBP11, an AGL15-like gene isolated from Solanum lycopersicum, enhances salt tolerance through an abscisic acid-independent signaling network in tomato [19]. Thus, MADS-box TFs have major significance in enhancing plant tolerance to various stresses.

Alfalfa (Medicago sativa L.) is widely cultivated in North America, Asia and other continents, with an area of more than 40 million hectares [20]. In the Netherlands, two-thirds of arable land has been used for alfalfa to develop grassland agriculture. Alfalfa is the fourth largest planted crop in the United States, after wheat, corn and soybean [21]. In China, alfalfa is planted in 14 provinces throughout the Northeast, Central North and Northwest regions of the country. An excellent local cultivated alfalfa cultivar ('XinJiangDaYe') with large leaves and an autotetraploid genome $(2 \mathrm{n}=4 \mathrm{x}=32)$ is widely planted in Xinjiang, Gansu, Qinghai and other provinces in China and has the highest resistance. Alfalfa has a high biomass and crude protein content and is rich in digestible nutrients and mineral elements, which greatly reduces the cost of feed supplementation for livestock production. Alfalfa is one of the key grasses for promoting agricultural production and economic development in arid and semiarid areas of China [22]. With the deterioration of the ecological environment in these areas, the development and quality of alfalfa are limited, and production is reduced by at least $10-20 \%$ due to multiple extreme conditions such as deficient water, freezing temperatures, and high salinity [23]. In 2020, the complete genome data of the autotetraploid cultivar XinJiangDaYe were published, generating a chromosome-level genome assembly with 32 chromosomes and high quality rather than eight chromosomes $[21,24]$. This assembly will provide a wide range of data resources for selecting key stress-related genes and improving alfalfa stress resistance by genetic engineering.

To date, the functions of the MADS-box gene family involved in abiotic stress have been widely reported in a variety of plants [25]. Large quantities of MADS-box genes have been identified and characterized in Oryza sativa $(n=75)$ [26], Pyrus $\times$ bretschneideri $(n=95)$ [27], A. thaliana $(n=109)$ [28], Zea mays L. $(n=142)$ [29], and Brassica rapa $(n=167)$ [30]. However, there have been no reports in terms of MADS-box genes involved in stress resistance in alfalfa. Cultivated alfalfa genomic data have been published, and a large amount of transcriptome data are available, providing a reliable experimental resource for the systematic study of MADS-box genes in alfalfa [31-33]. Based on these data, in this study, $M A D S$-box genes in the genome of the autotetraploid cultivar XinJiangDaYe were identified and characterized. Detailed information on the physicochemical properties, phylogenetic relationships, gene structures, motif composition, chromosomal map, synteny and cisregulatory elements of $M S M A D S$-box genes was generated. In addition, the tissue-specific expression patterns and the differential expression of MsMADS-box genes under various abiotic stresses were comprehensively surveyed. The framework of content in this study was shown in Fig. 1. Our study is the first to report on the $M A D S-b o x$ gene family in autotetraploid cultivated 


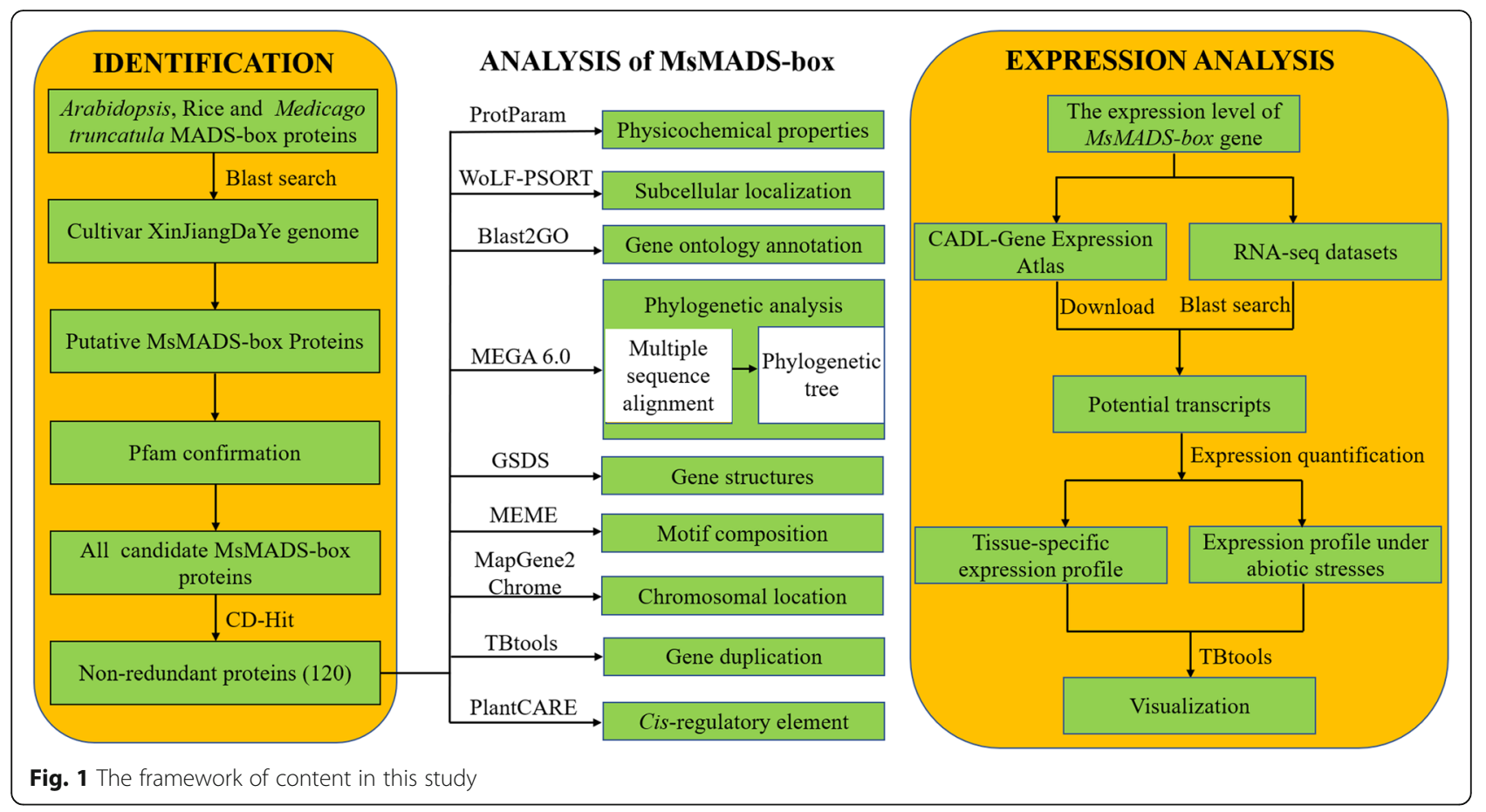

alfalfa, which provides valuable information for exploring the functions and molecular mechanisms underlying abiotic stress tolerance in this important economical crop.

\section{Results \\ Identification and Gene Ontology (GO) analysis of MsMADS-box genes in alfalfa}

A total of 120 MADS-box genes were identified in the alfalfa genome after removal of redundant sequences and were renamed from MsMADSO01 to MsMADS120 according to their order of appearance in the genome annotation file. Information on MsMADS-box protein sequences and gene sequences is provided in Additional file 1: Table S1. The physicochemical properties of MsMADS-box proteins were investigated by ExpasyProtParam, and detailed information is summarized in Additional file 1: Table S2. The lengths of the identified MsMADS-box proteins ranged from 95 to 1288 amino acids (AAs). The molecular weights (MWs) of the MADS-box proteins ranged from 11588.13 to 147858.01 $\mathrm{Da}$, and the pIs ranged from 4.69 to 9.87 . The instability indices of most MsMADS-box proteins (98 of 120) were higher than 40, which suggested that they were not stable proteins. The grand average of hydropathicity of all MsMADS-box proteins was negative $(<0)$, indicating that they were soluble hydrophilic proteins. Moreover, the subcellular localization analysis of the MADS-box proteins showed that most of them were located in the nucleus, followed by the mitochondrial matrix space and the plasma membrane.
To figure out the functional classification of all $M s M A D S-b o x$ genes, GO annotation was analyzed by Blast2GO 5.2 software. All the MsMADS-box genes were categorized into biological process, molecular function, and cellular component categories, and the detail information was summarized in Table 1 and Additional file 1: Table S3. For the biological process category, four terms were assigned to all MsMADS-box genes, including "regulation of biological process", "metabolic process", "biological regulation", and "cellular process", and 108 MsMADS-box genes were assigned to "positive regulation of biological process". Regarding the molecular function category, totals of 119 and 120 MsMADS-box genes were assigned to "binding" and "transcription regulator activity" terms, respectively. All MsMADS-box genes were classified as "cellular anatomical entity" term, which was the only one term identified in the cellular component category.

\section{Phylogenetic analysis, gene structures and motif composition of MsMADS-box genes}

To examine the evolutionary relationships among MsMADS-box proteins, a phylogenetic tree was constructed between alfalfa and Arabidopsis MADS-box proteins by MEGA-X using the NJ method. The family of 75 type-I MsMADS-box genes was divided into the $\mathrm{M} \alpha, \mathrm{M} \beta$, and $\mathrm{M \gamma}$ subgroups and the 45 type-II MsMADS-box genes were divided into 13 subgroups (MIKC", GGM13, AGL17, STMADS11, AGL15, AG, AGL12, DEF + GLO, TM3, FLC, SQUA, AGL6, and AGL2) according to the classification of MADS-box 
Table 1 Gene ontology (GO) analysis of 120 MsMADS-box genes

\begin{tabular}{lllr}
\hline GO term & Ontology & Description & Gene number \\
\hline GO:0050789 & Biological Process & regulation of biological process & 120 \\
GO:0048518 & Biological Process & positive regulation of biological process & 108 \\
GO:0008152 & Biological Process & metabolic process & 120 \\
GO:0065007 & Biological Process & biological regulation & 120 \\
GO:0009987 & Biological Process & cellular process & 120 \\
GO:0005488 & Molecular Function & binding & 119 \\
GO:0140110 & Molecular Function & transcription regulator activity & 120 \\
GO:0110165 & Cellular Component & cellular anatomical entity & 120 \\
\hline
\end{tabular}

genes in Arabidopsis (Fig. 2 and Additional file 2: Fig. S1). However, subgroups GGM13 and FLC had no MsMADS-box members, subgroup AGL12 contained the smallest number of MsMADS-box proteins (only one), and subgroup $\mathrm{M} \gamma$ contained the largest number.

Gene structure analysis showed that the number of exons in MsMADS-box genes varied from one to 17
(Additional file 2: Fig. S2). Among the 120 MsMADSbox genes, MsMADS117 possessed the highest number $(n=17)$ of exons, followed by MsMADS059 and MsMADS062 $(n=16)$ and MsMADS144 $(n=15)$. Moreover, a total of $62 M s M A D S-b o x$ genes had only one exon, and the number of introns varied among different subfamilies. The type-II MsMADS-box genes contained

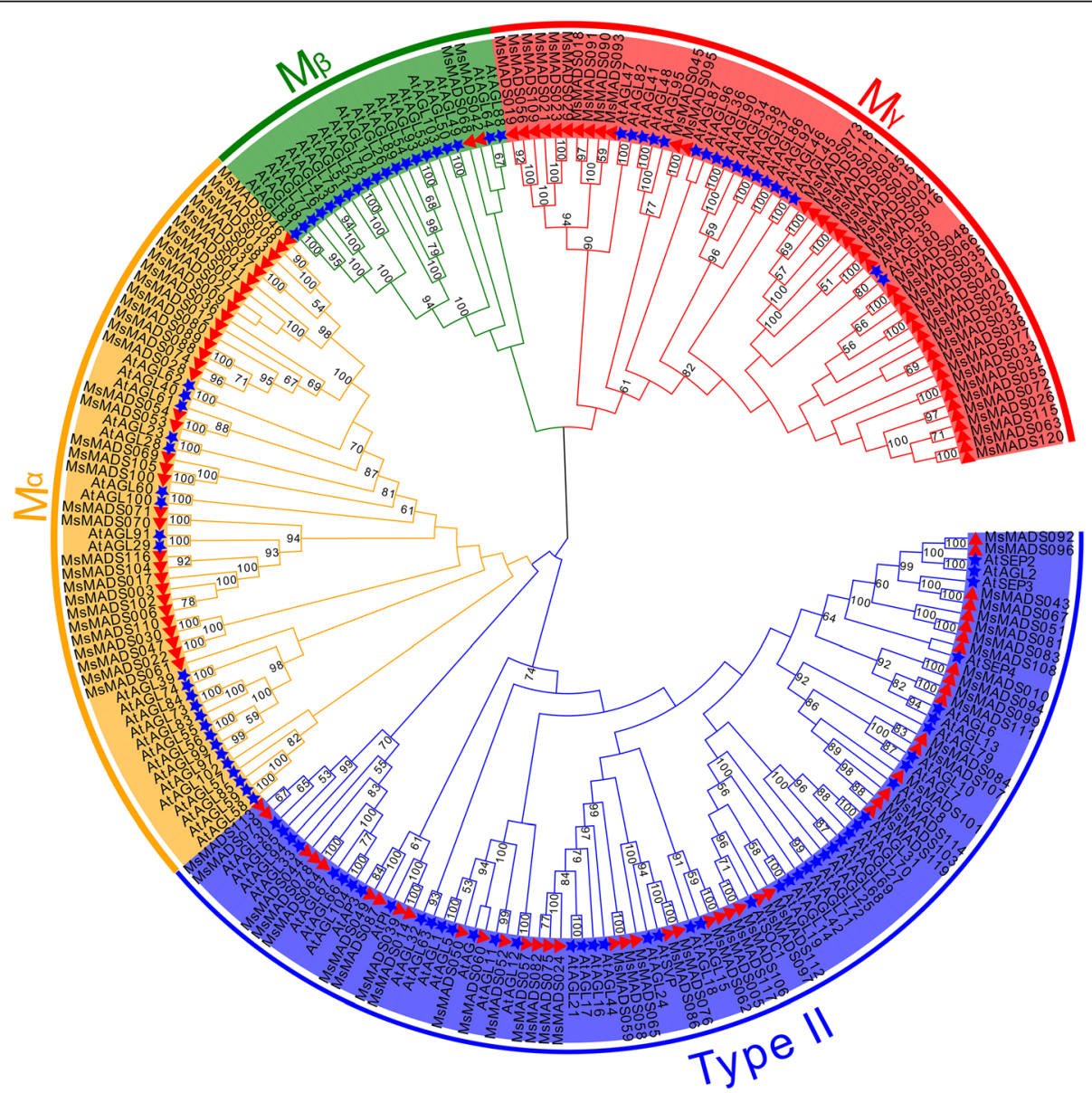

Fig. 2 Phylogenetic trees of alfalfa and Arabidopsis MADS-box proteins constructed in MEGA-X using the neighbor-joining method. The tree is divided into four groups, indicated by different colors. The blue star and red triangle shapes represent Arabidopsis and alfalfa MADS-box genes, respectively 
multiple introns, while most type-I MsMADS-box genes had zero to two introns, except for MsMADSO42 and MsMADSO68 from the $\mathrm{M} \beta$ subfamily, which contained four and five introns, respectively, and MsMADS090 from the M $\alpha$ subfamily, which contained six introns.

To explore the distribution and structural diversification of conserved motifs of alfalfa MsMADS-box proteins, the MEME tool was applied to identify conserved motifs, most of which played significant roles in proteinprotein interactions and transcriptional activity. A total of 20 conserved motifs were identified and renamed motifs 01 to 20, some of which exhibited similar compositions and positions in the same subfamilies of MsMADSbox genes (Additional file 1: Table S4 and Additional file 2: Fig. S3). According to the NCBI CDD (https://www. ncbi.nlm.nih.gov/Structure/cdd/wrpsb.cgi) search results, motif 01 and motif 04 were recognized as the MADS domain and the $\mathrm{K}$ domain, respectively. Motif 01, a highly conserved motif, consisted of approximately 60 amino acids in the N-terminus of type-I MsMADS-box proteins, except for MsMADS04, MsMADS027, MsMADS033, MsMADS034, and MsMADS068. Motif 04 , which plays a significant role in protein-protein interactions in MADS-box gene family, appeared in all type-II MsMADS-box genes.

\section{Chromosomal mapping and synteny analysis of MsMADS- box genes in alfalfa}

All MsMADS-box genes were unevenly distributed on the 32 chromosomes of alfalfa, except for MsMADS118, MsMADS119, and MsMADS120 (Fig. 3). Chromosome 3.4 (Chr 3.4) contained the largest number of MADSbox genes $(n=11)$, Chr 4.4 contained 10 members, Chr 5.4 and Chr 1.2 each had 7 members, and Chr 7.2 had no MsMADS-box genes. In addition, there were six MsMADS-box genes located on Chr 1.3, Chr 3.3, Chr 5.3, Chr 8.1, and Chr 8.4, and five MsMADS-box genes were found on Chr 1.4, Chr 2.4, Chr 3.2, and Chr 4.3. Only one MsMADS-box gene was distributed on Chr 1.1, Chr 2.3, Chr 4.1, Chr 5.1, Chr 6.1, Chr 6.2, Chr 6.4, Chr 7.3, and Chr 8.3.

We used TBtools software to perform collinearity analysis to detect the gene duplication events of MADS-box genes in alfalfa. A total of nine pairs of duplicated segments in MsMADS-box genes and four groups of tandemly duplicated MsMADS-box genes (MsMADS002/ MsMADSO04, MsMADS009/MsMADS013, MsMADS033/MsMADS034, and MsMADSO70/ MsMADS071) were identified (Fig. 4).

\section{Cis-regulatory element analysis of MsMADS-box gene promoters}

Cis-regulatory elements are specific DNA sequences that are located upstream of gene coding sequences and regulate the expression of stress-responsive genes by binding with TFs. Thus, we explored the distribution of six cis-regulatory elements in the promoter regions of these changed MsMADS-box genes during abiotic stresses. The GT1 motif had the largest number of cisregulatory elements, with 168 , followed by ABREs $(n=$ $165)$, MBSs $(n=101)$, CGTCA motifs $(n=100)$, TC-rich repeats $(n=63)$, and LTRs $(n=38)$ (Additional file 2: Fig. S4). Moreover, we found that MsMADS033, MsMADS051, and MsMADS075 contained all six cisregulatory elements, while MsMADS048, MsMADS056, MsMADSO73, and MsMADSO84 had only one cis-regulatory element each.

\section{Expression pattern analysis of MsMADS-box genes in $M$. sativa tissues}

Tissue-specific expression is associated with the specific function of MADS-box genes in particular tissues. Thus, we used microarray datasets of the alfalfa B47 genotype obtained from the CADL-Gene Expression Atlas to assess the expression levels of MsMADS-box genes in six tissues, including leaf, flower, pre-elongated stem, elongated stem, root, and nodule tissues, of alfalfa. A total of 95 MsMADS-box genes were identified, and the remaining 25 genes were not found in the dataset. A heatmap of MsMADS-box genes was generated by using TBtools software, and 95 MsMADS-box genes were divided into eight groups, namely, A to $\mathrm{H}$, based on their expression levels in different tissues (Fig. 5 and Additional file 1: Table S5). Most of the MsMADS-box genes had variable expression profiles, except group B, which was not expressed in any tissues. Groups C, E, F, G, and $\mathrm{H}$ showed the highest expression levels in elongated stems, nodules, flowers, pre-elongated stems, and leaves, respectively. Groups A and D exhibited variable expression patterns in these six tissues.

\section{Expression analysis of MsMADS-box genes in response to abiotic stresses}

To detect dynamic changes in the expression levels of MsMADS-box genes under cold, drought, and salt stresses and ABA treatment, BLASTN against four transcriptome datasets previously collected by our laboratory was performed. A total of $104 M s M A D S$-box genes were identified under these four treatments. A heatmap of these identified MsMADS-box genes under cold treatment was separately constructed because the sequenced tissue samples were different from those in the other three treatments. The results are shown in Additional file 1: Table S6 and Additional file 2: Fig. S5. In total, 104 MsMADS-box genes were divided into eight groups, namely, groups A to $\mathrm{F}$, according to their expression patterns at different time points under cold treatment. The expression of group A significantly increased at 0 to 


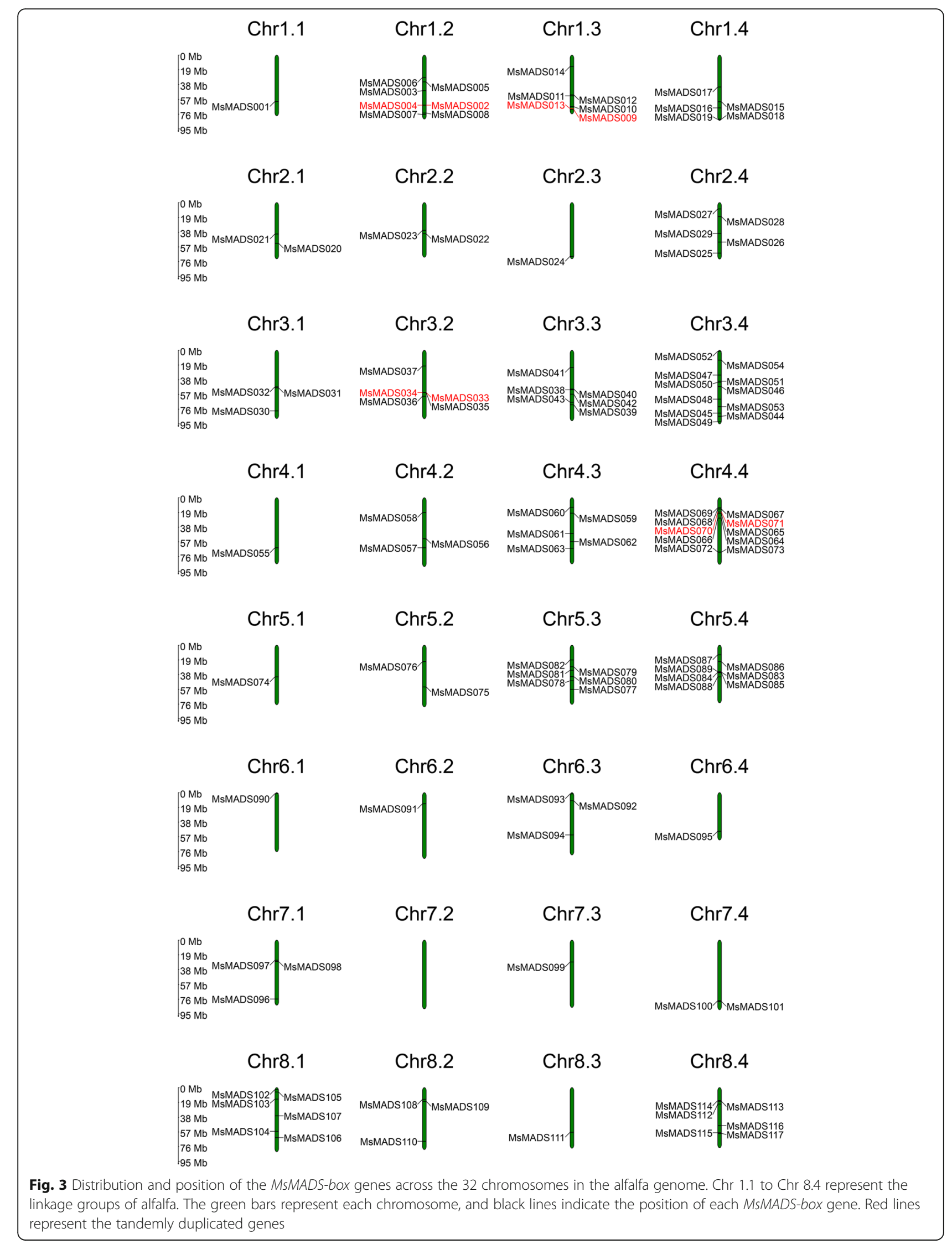




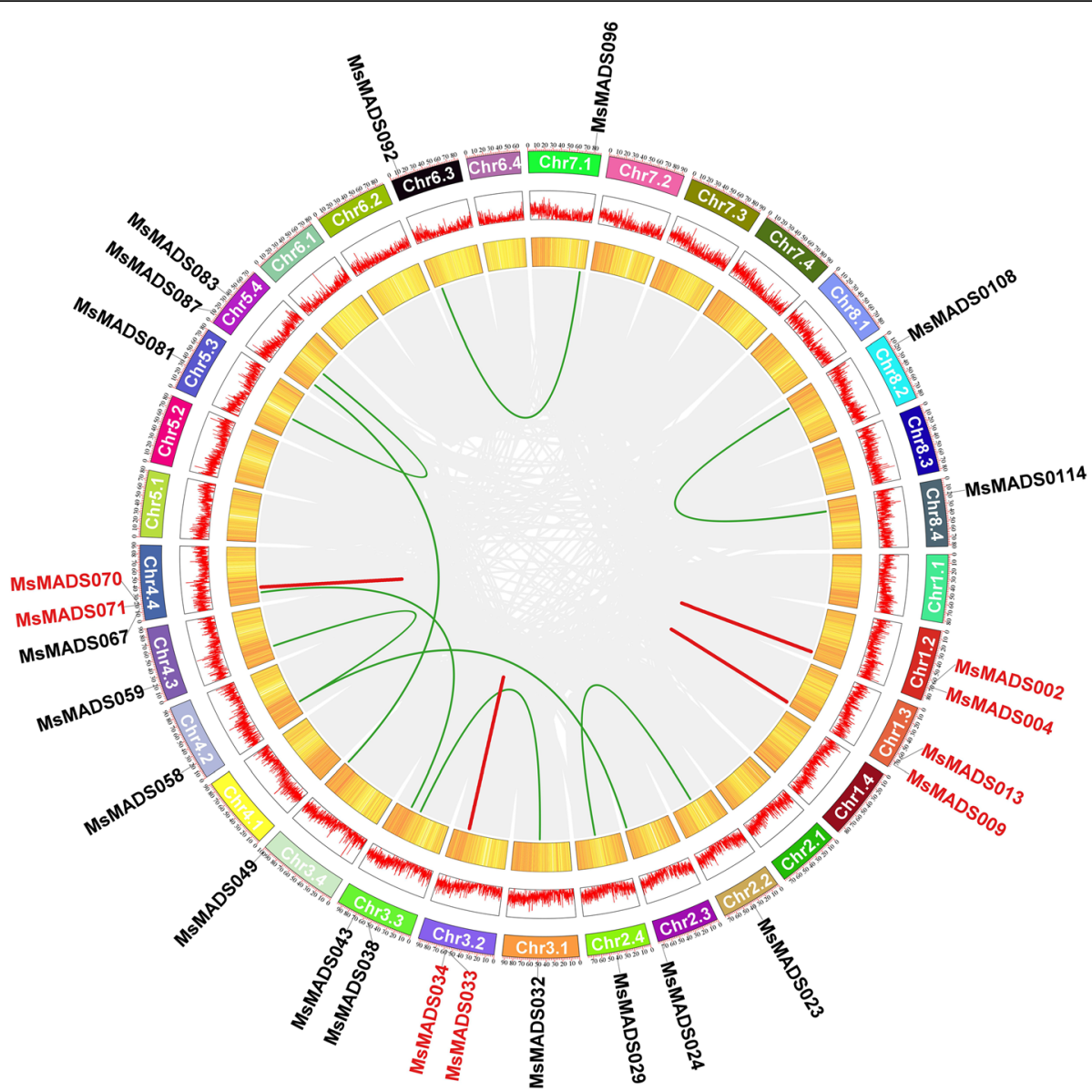

Fig. 4 Synteny analysis of MSMADS-box genes in alfalfa. Gray lines represent all synteny blocks in the alfalfa genome. Green and red lines indicate the duplicated MSMADS-box gene pairs and tandemly duplicated MSMADS-box genes in alfalfa, respectively. Yellow and red boxes indicate the gene density and expression levels of MSMADS-box genes, respectively

$2 \mathrm{~h}$ and gradually declined at later time points. The expression levels of groups B and D were significantly upregulated under cold stress and peaked at $2 \mathrm{~h}$. Group $\mathrm{C}$ did not exhibit expression at any time point under cold treatment. Group E showed downregulated expression at the treatment times. The expression of group $\mathrm{F}$ was decreased from 0 to $6 \mathrm{~h}$ and increased at $24 \mathrm{~h}$.

For the other three treatments, the expression profiles of 104 MsMADS-box genes are shown in Additional file 2: Fig. S6, and the results were similarly classified into groups A to I. For ABA treatment, most MsMADS-box genes were either inhibited or not expressed at some time points, such as those in groups A, B, C, D, and E. Group F showed significantly upregulated expression when subjected to ABA treatment. The expression levels of groups G, H and I were significantly upregulated at $3 \mathrm{~h}$ and reached their peak values at $12 \mathrm{~h}$.

Under drought treatment, most of the genes showed significant upregulation when subjected to drought treatment and reached their peak values at $1 \mathrm{~h}$, such as those in groups B and D, which indicated that these genes can quickly respond to drought stress. The expression levels of groups $\mathrm{A}, \mathrm{E}$, and $\mathrm{H}$ were significantly upregulated at $6 \mathrm{~h}$ and declined at later time points. The expression levels of groups $\mathrm{F}$ and $\mathrm{G}$ gradually increased under exposure to drought stress from 1 to $12 \mathrm{~h}$, suggesting positive regulation. The expression of group I was inhibited or repressed from 1 to $24 \mathrm{~h}$, which was different from that in the other groups. Notably, almost all groups showed the minimum relative expression or recovered to the initial transcription level upon drought removal for 1 or $12 \mathrm{~h}$.

Salt treatment also led to serious increases in the transcription levels of groups A, B, C, and D at $1 \mathrm{~h}$, similar to the expression profiles under drought stress. The expression levels of groups E, F, and G reached the minimum upon salt removal for $12 \mathrm{~h}$. The expression pattern of group $\mathrm{H}$ was distinct from those of the other groups, which exhibited a dynamic change during salt treatment. For group I, in which 


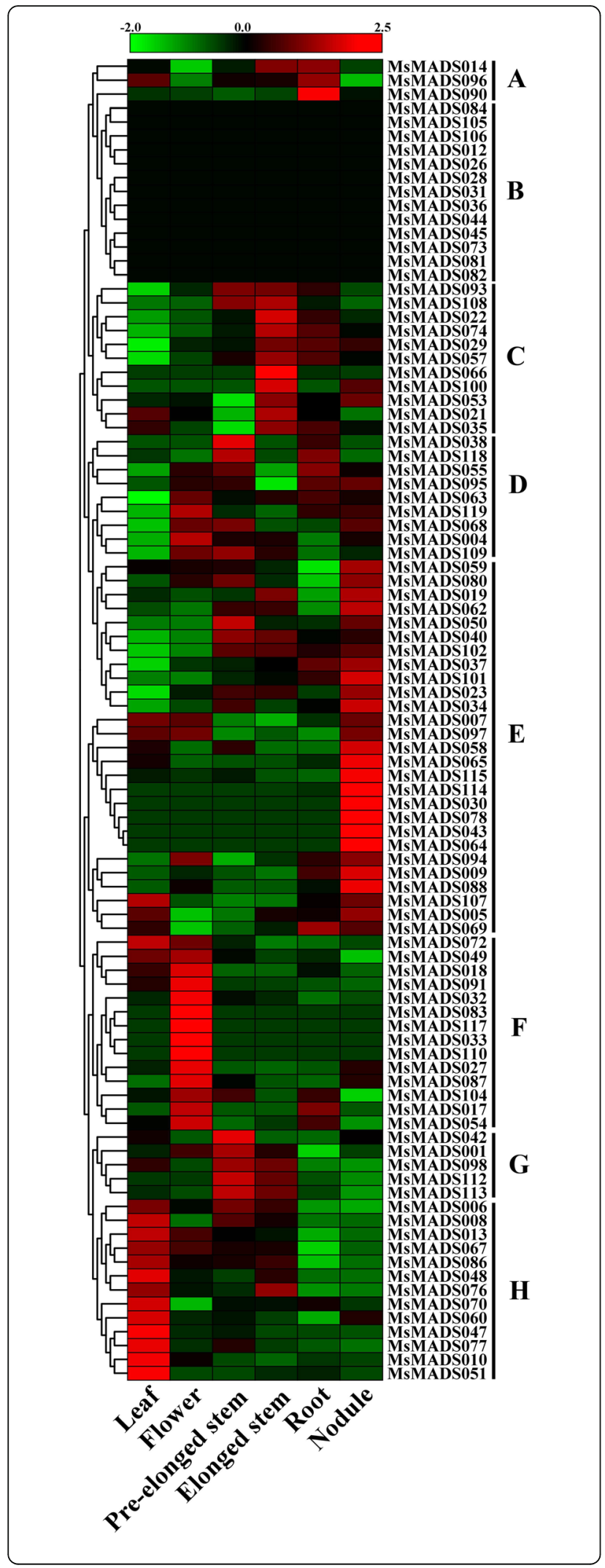

Fig. 5 Expression levels of all MSMADS-box genes of alfalfa in six tissues (leaf, flower, pre-elongated stem, elongated stem, root, and nodule). The red and green colors indicate the expression levels of MSMADS-box genes from high to low, and black indicates the median expression level in the heatmap. Groups A to $\mathrm{H}$ exhibited eight expression patterns of MsMDAS-box genes in six tissues. The heatmap was generated by using TBtools software

expression gradually increased, the peak value appeared at $12 \mathrm{~h}$ of salt removal.

\section{qRT-PCR validation of gene expression}

To further verify the RNA-Seq data, eight MsMADS-box genes (MsMADS001, 029, 059, 062, 065, 075, 090, and 112) that were significantly induced by cold, drought, and salt stresses and ABA treatment were selected for qRT-PCR validation, and the Ct values of qRT-PCR were provided in Additional file 1: Table S7. The expression trends of most of the tested MsMADS-box genes were consistent with the RNA-Seq analysis results (Figs. 6, 7 and 8, and 9). Expression of most of the tested genes was upregulated upon exposure to cold, drought, and salt stresses and ABA treatment, indicating positive regulation. For example, the expression levels of MsMADS001 and MsMADS075 were gradually upregulated with time under ABA treatment, which was similar to the RNA-Seq analysis results. The expression of the MsMADSO75 gene showed a trend of initially increasing and then decreasing under drought treatment compared with the control in both the RNA-Seq and qRT-PCR results.

In addition, to examine the effect of circadian rhythm for gene expression, we performed qRT-PCR analysis of eight MsMADS-box genes in plants grown without treatments and these results were shown in Additional file 2: Figs. S7, S8 and S9. we found that the expression level of few MsMADS-box genes showed circadian rhythm, and the fold change of expression level was not significant. For example, in the absence of drought and salt treatments, the expression level of MsMADSOO1 decreased initially, followed by an increased, but then again decreased, while the expression level of MsMADS001 exhibited a trend of gradual increase, and showed a significant difference compared with CK group under drought and salt treatments. Moreover, after ABA treatment, the expression trend of MsMADS001 was opposite to that of untreated, indicating that the expression of MsMADS001 was mainly affected by abiotic stress rather than circadian rhythm. It is worth noting that the expression of MsMADS029 showed a similar fold change and pattern between salt treatment and without salt treatment, suggesting that the expression of MsMADSO29 may be mainly affected by circadian rhythm rather than stress. Similarly, the expression 


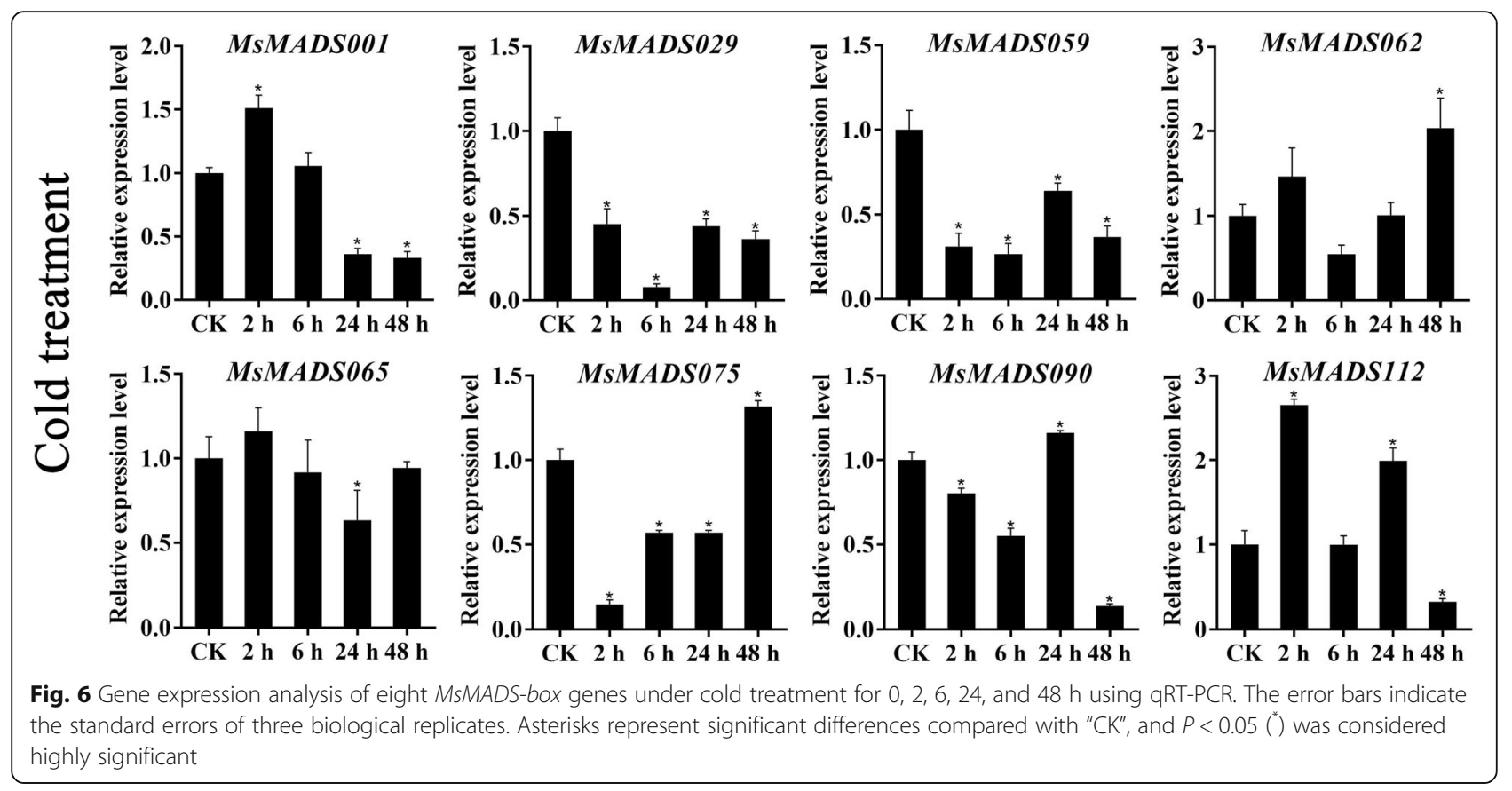

pattern of MsMADS065 under cold treatment was similar to without cold treatment, indicating that MsMADS065 was also mainly related to circadian rhythm.

\section{Discussion}

MADS-box TFs are one of the most widely studied superfamilies in plants. To date, most studies on MADSbox function have focused on the regulation of plant vegetative and reproductive development, floral organogenesis and flowering time [34]. Some MADSbox TFs involved in stress-responsive processes have been found in many plants [19]. For example, many MADS-box proteins in wheat were induced under abiotic stress [15], and CaMADS isolated from pepper was also rapidly upregulated by high temperature and salt stress as well as some plant exogenous hormones [35]. However, there have been no studies on the molecular function of MADS-box TFs in response to abiotic stress in alfalfa. Therefore, this study was focused on

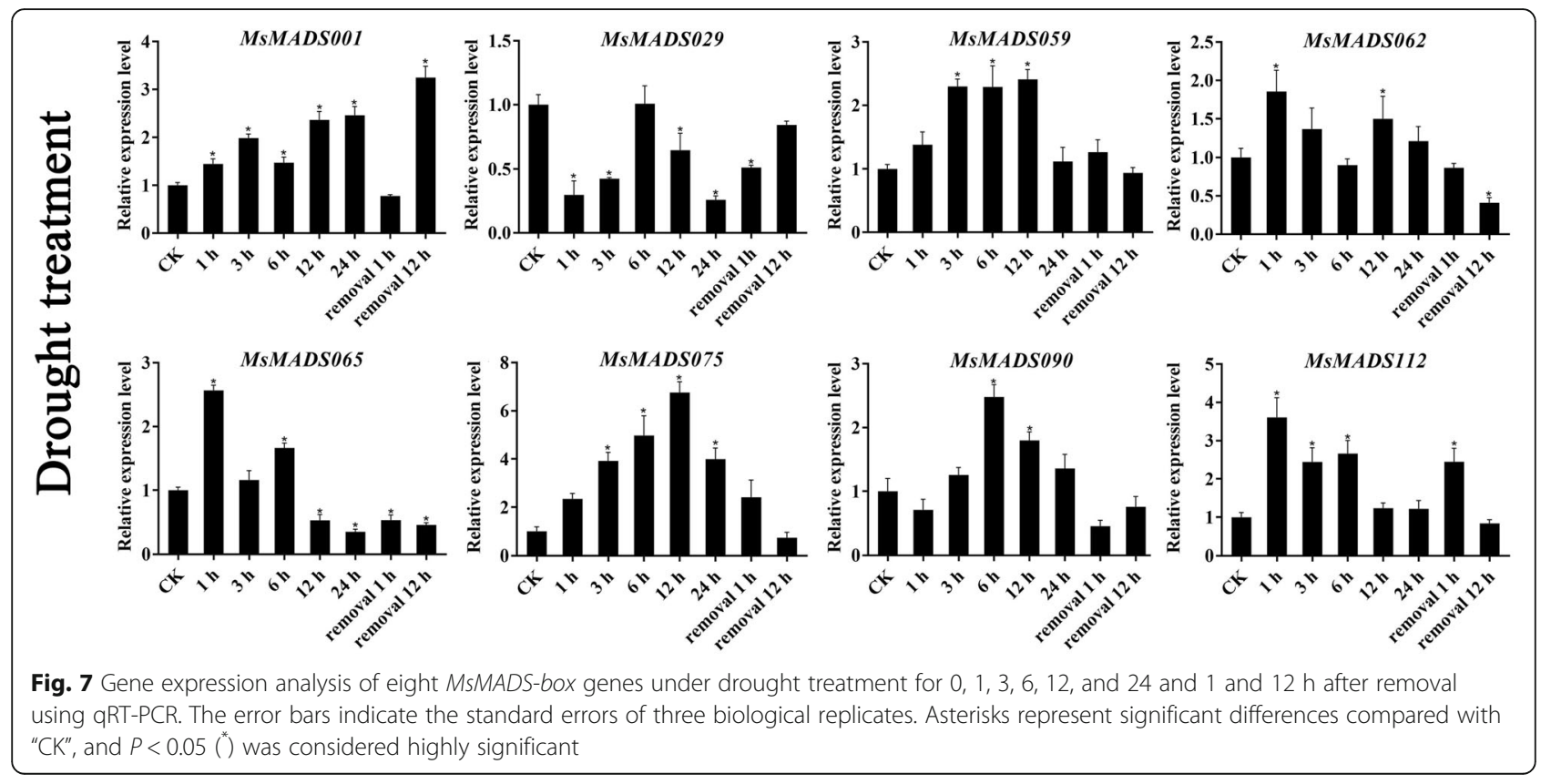




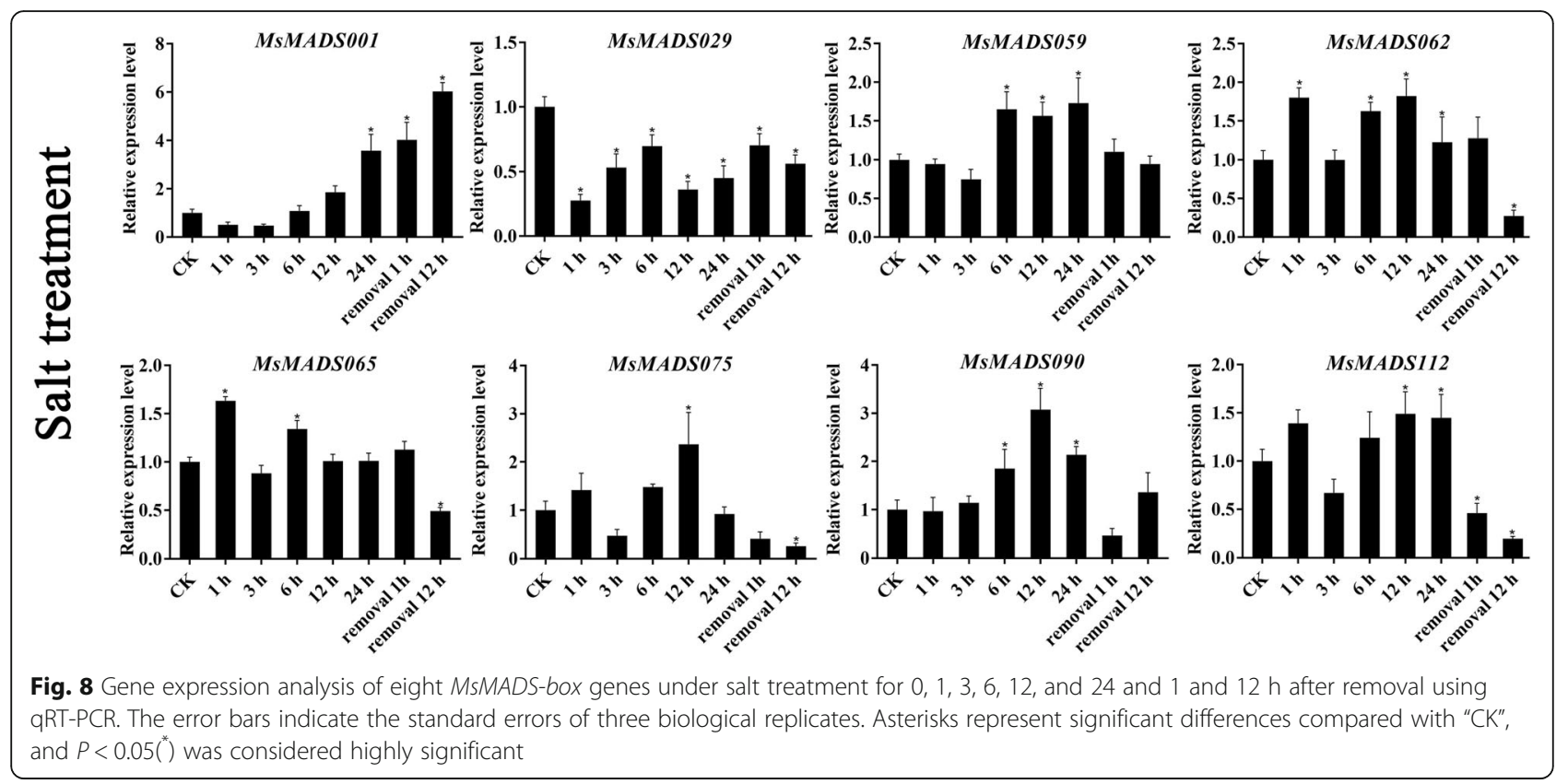

systematically exploring the potential molecular functions of MsMADS-box genes. First, we investigated the features of MsMADS-box genes by using genomewide identification. Moreover, the gene structure, motif composition, phylogenetic relationships, chromosomal location, synteny, cis-regulatory elements, tissue-specific expression and responses to cold, drought, and salt stresses and ABA treatment were investigated. These results will enrich our understanding of the MsMADS-box gene family and provide a foundation for further exploring the functions of MsMADS-box genes.

In our study, a total of 120 MsMADS-box genes were identified in the alfalfa genome. The number of MADS$b o x$ genes in alfalfa was higher than those in $A$. thaliana $(n=109)$ [28], Oryza sativa $(n=75)$ [26], Lactuca sativa $(n=82)$ [36], Erigeron breviscapus $(n=44)$ [37], and Phyllostachys edulis $(n=42)$ [38] but lower than those in tomato $(n=131)$ [39], Zea mays $(n=142)$ [29], Brassica rapa $(n=167)$ [30], and Gossypium hirsutum $(n=207)$

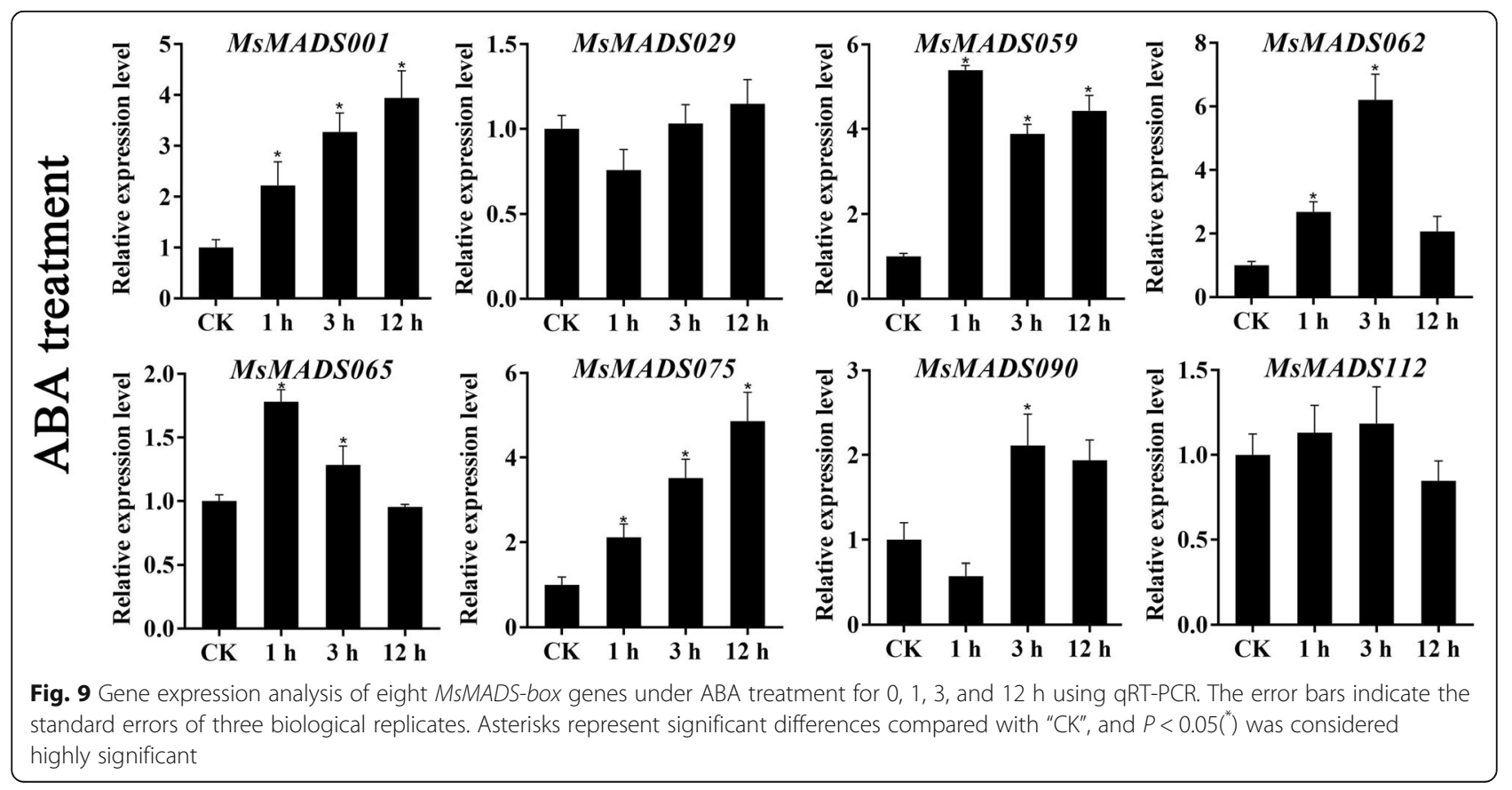


[25]. The nucleotide sequence lengths, molecular weights and theoretical isoelectric points of the MsMADS-box genes varied. GO annotation analysis indicated that most of MsMADS-box genes were related to "regulation of biological process", "positive regulation of biological process", "metabolic process", "biological regulation", and "cellular process", which was consistent with the findings in Helianthus tuberosus L. [40]. In addition, many GO terms were also assigned to "Molecular Function" and "Cellular Component", including "binding", "transcription regulator activity", and "cellular anatomical entity", which suggesting that MsMDAS-box genes are involved in various biological processes. The gene structure and motif composition were conserved in the same subgroups, indicating that these genes may have subgroup-specific functions [39]. Phylogenetic analysis revealed that $75 M s M D A S-b o x$ genes belong to type-I genes, which was higher than the numbers in Arabidopsis and rice, suggesting that type-I genes have a higher duplication rate during evolution [41]. In contrast to those in A. thaliana and rice, the alfalfa MADS-box gene family lost the GGM13 subgroup, which is involved in seed pigmentation and endothelial cell development [42]. This difference may be due to interspecific differences or other undetermined causes.

It is well known that gene duplication plays an important role in the rapid expansion and evolution of gene families [27]. There were nine pairs of segmental duplications and four pairs of tandem duplications in the MsMADS-box genes. Duplication of MADS-box genes has been found in many species, including Arabidopsis thaliana, rice and tomato [39]. Chromosome location analysis showed that the MsMADS-box genes were unevenly distributed on 32 chromosomes. Moreover, the MADS-box gene family in alfalfa was found to have a gene cluster on $\mathrm{Chr}$ 3.4, which indicated that the MsMADS-box gene family was characterized by a gene duplication phenomenon. Ren et al. identified 110 MIKC-subgroup genes in Gossypium hirsutum, which were distributed on 25 chromosomes, and no MIKCsubgroup genes were distributed on chromosome D01 [43]. In our study, $45 \mathrm{MIKC}$-subgroup genes were identified in the alfalfa genome, and no MIKC genes were found on many chromosomes, suggesting that the differences in mapping results may be related to the reference genomes used. The promoter regions of MADS-box gene family members in alfalfa contained a variety of response elements, mainly includes hormone-related elements and stress-related elements, among which the GT1 motif elements were the most abundant, followed by ABREs. This result was similar to the experimental discovery of MADS-box genes in Eudicots [44]. In fact, a lot of studies have also been verified that common cis-regulatory elements also existed in the promoter region of stress- responsive genes, such as $M Y B, W R K Y$, and Dof genes [45-47]. Moreover, previous studies have reported that ABREs are the main cis-regulatory elements of ABA response genes, which can be activated to improve plant stress tolerance through interacted with upstream TFs [48]. Therefore, these results further suggest the probable function of MsMADS-box genes in response to abiotic stresses, and further study need to verify their potential roles.

MADS-box gene family is the most powerful TFs that regulate fruit development and ripening and have been extensively studied in A. thaliana [28] and perennial woody plants such as Malus x domestica [49], Prunus persica [50], Pyrus $\times$ bretschneideri [27] and Morella rubra [51]. Gene expression profiles provide important information for gene function exploration. As a result, we found that 58/95 MsMADS-box genes were expressed in all six examined tissues, while some of the other genes showed tissue-specific expression patterns. For example, MsMADS033, MsMADS083, MsMADS110, and MsMADS117 were expressed only in flowers, suggesting that these genes play key roles in the regulation of floral organogenesis and flowering time. This phenomenon was also observed in rice [52], wheat [53], and soybean [54]. In addition, tissue-specific overexpression of $M A D S-b o x$ genes has been reported to regulate flowering time. For example, overexpression of TaMADS in Arabidopsis leads to early flowering [18], and overexpression of NtMADS133 in tobacco significantly reduces the flowering time from 58 days to 38 days [55]. Moreover, MsMADS009, MsMADS057, and MsMADS095 were expressed at high levels in all tested tissues (FPKM $>20$ ), suggesting that these genes play important roles throughout the plant life cycle. Therefore, we speculate that MADS-box genes with tissue-specific expression have important regulatory functions in related tissues, which provides insight into how we can utilize MADS-box genes to promote tissue growth and development.

The related role of MADS-box TFs in plant stress resistance has been reported in earlier studies in various plants, such as rice [56], tomato [14], sheepgrass [57], Brassica rapa [30], and wheat [15]. For example, in maize, the expression of ZZM7-L, an AGL12-like MADS-box gene, was upregulated by $\mathrm{NaCl}$, cold, and mannitol treatments and downregulated by exogenous ABA, and overexpression of ZZM7-L in Arabidopsis thaliana resulted in a significantly lower germination rate of the transgenic plants than of the wild type, suggesting that ZZM7-L had a negative function [29]. Similarly, the expression of CaMADS was induced by low temperature, salt, and $\mathrm{ABA}$, and CaMADS-overexpressing Arabidopsis plants were more tolerant to these stresses than WT plants [39]. In Ginkgo biloba, a recent 
study also demonstrated that GbMADS9, a GGM13clade MADS-box protein, enhanced the tolerance of transgenic Arabidopsis plants to osmotic stress, suggesting that GbMADS9 had a positive function in response to osmotic stress [58]. In this study, the expression patterns of 104 MsMADS-box genes under multiple abiotic stresses were determined in previous RNA-Seq data. Most MsMADS-box genes showed different responses to abiotic stress at the transcriptional level. In addition, we found that MsMADSO01, MsMADS075 and MsMADS090 were significantly induced by drought and salt stresses, suggesting that these genes might have multiple stress resistance-related functions in alfalfa. The expression levels of eight MsMADS-box genes under cold, drought, and salt stresses and ABA treatment were studied by qRT-PCR. However, there were variations in the degrees of gene expression fold change between the RNA-seq and qRT-PCR analyses, which also appeared in several previous studies $[59,60]$ and may be due to genetic diversity among alfalfa individuals [31]. Moreover, we performed qRT-PCR experiments on the expression of eight MsMADS-box genes at different time points in the plants grown without stresses treatment to investigate whether MsMADS-box genes expression was induced by circadian rhythm. These results showed that only small proportion of MsMADS-box gene was involved in circadian rhythm, which was consistent with the found in pineapple [61]. In conclusion, the transcriptional responses of MsMADS-box genes to cold, drought, and salt stress and ABA treatment will provide a solid foundation for further studies of abiotic stress response mechanisms in alfalfa.

\section{Conclusions}

In this study, we comprehensively and systematically analyzed the MADS-box transcription factor family in the autotetraploid cultivated alfalfa genome. A total of 120 $M s M A D S-b o x$ genes were extensively identified via genome-wide screening. The physicochemical properties, phylogenetic relationships, exon-intron structures, conserved motifs, chromosomal location, gene duplication, cis-regulatory elements, tissue-specific expression patterns, and expression levels under cold, drought and salt stress and ABA treatment were analyzed. Expression analysis of MsMADS-box genes provides insights for further understanding the molecular mechanisms of MsMADS-box genes underlying development and responses to abiotic stress in autotetraploid cultivated alfalfa. This study provides clues for understanding the potential molecular function of MADS-box gene in alfalfa, and lay a foundation for enhancing alfalfa tolerance to abiotic stresses by overexpressing, RNA interference, or CRISPR/Cas9 technology in the future.

\section{Methods \\ Identification and Gene Ontology (GO) analysis of the MsMADS-box gene family in alfalfa}

The genome assembly files of alfalfa were downloaded from the figshare projects (https://figshare.com/projects/ whole_genome_sequencing_and_assembly_of_ Medicago_sativa/66380). To more comprehensively investigate the MADS-box family genes, the MADS-box protein sequences of Arabidopsis and rice were obtained from The Arabidopsis Information Resource (TAIR9) (www.arabidopsis.org) database and the Rice Genome Annotation Project (http://rice.plantbiology.msu.edu/), respectively. Moreover, to further accurately identify the MADS-box gene family in the alfalfa genome, the MADS-box protein sequences of Medicago truncatula, a model plant for legumes, were acquired from the LISLegume Information System (https://legumeinfo.org/ home). First, these protein sequences were used as query sequences for BLAST analysis against the cultivar XinJiangDaYe genome database with an E-value cutoff of 0.00001. Furthermore, a hidden Markov model (HMM) profile of MADS-box (PF00319) was downloaded from the Pfam database (http://pfam.xfam.org/) for further confirmation of alfalfa MADS-box proteins with HMME R 3.0 software using default parameters, and an E-value of 1.0 was set as the threshold. The CD-HIT web server (http://www.bioinformatics.org/cd-hit/) with default parameters was used to remove redundant data. Subsequently, these purified sequences were considered MsMADS-box genes for further analysis. The ProtParam tool (https://web.expasy.org/protparam/) was used to determine the physicochemical properties of each MsMADS-box protein, including the molecular weight $(\mathrm{MW})$, theoretical isoelectric point (pI), instability index and grand average of hydropathicity (GRAVY) index. In addition, the subcellular localization of all MsMADS-box genes was predicted by WoLF-PSORT (https://www. genscript.com/wolf-psort.html). In addition, GO annotation was performed to investigate the functional role of MsMADS-box genes using Blast2GO 5.2 software, with default parameters [62].

\section{Phylogenetic analysis, gene structures and motif composition of MsMADS-box genes}

To analyze the evolutionary relationships of the obtained $M A D S$-box genes in alfalfa, multiple sequence alignment was performed by Clustal W (http://www.clustal.org/ clustal2/) with default parameters, and a phylogenetic tree of 120 alfalfa MADS-box and 107 Arabidopsis $M A D S-b o x$ genes was then constructed using the neighbor-joining (NJ) method in MEGA 6.0 software (https://www.megasoftware.net/) with a p-distance model, 1000 bootstrap replicates, and pairwise detection. All MsMADS-box genes were classified into the $M \alpha, M \beta$ 
and $\mathrm{M} \gamma$ subgroups and type-II groups according to their evolutionary relationships with MADS-box genes in Arabidopsis.

Understanding the gene structure can help reveal gene functions, regulation and evolution. To investigate the diversity of gene structures of MADS-box genes, the Gene Structure Display Server (GSDS) (http://gsds.cbi. pku.edu.cn) program was applied. The MADS domain is the core of MADS-box TFs, which can activate the downstream genes through interact with the promoter of them. The MEME 4.12.0 online tool (http://memesuite.org) was used to identify the conserved motifs of these 120 alfalfa MADS-box proteins. The parameters were set as follows: the maximum number of motifs was 20; zero or one occurrence per sequence (zoops) was selected as the site distribution; the minimum and maximum motif widths were set to 6 and 200, respectively; and other parameters were set to the default values.

\section{Chromosomal mapping and gene duplication analysis} In order to better recognize the genomic distribution of MsMADS-box genes, MapGene2Chrome (http://mg2c. iask.in/mg2c_v2.0/) was used to draft a chromosomal location map of the MADS-box genes based on the genome annotation files of alfalfa. Gene duplication is a major source to produce new genes and lead to the proliferation and diversification of TFs genes in the plant kingdom. TBtools software was used to perform a collinearity analysis of 120 MsMADS-box genes in order to detect gene duplication events [63].

\section{Cis-regulatory element analysis}

In-depth analysis of the cis-regulatory elements contained in MsMADS-box genes will provide further insight into their roles in plant stress resistance. The PlantCARE database (http://bioinformatics.psb.ugent. be/webtools/plantcare/html/) was used to identify the cis-regulatory elements within the sequence $2000 \mathrm{bp}$ upstream of transcriptional initiation sites of $M s M A D S-b o x$ genes whose expression changed under abiotic stresses. A total of six cis-regulatory elements known to be associated with stress and hormones have been identified in the promoter regions of MADS-box genes in alfalfa, including ABRE, TC-rich repeats, MBS, LTR, GT1-motif, and CGTCA-motif, which are involved in abscisic acid-responsive, defense- and stress-responsive, drought-inducible, low-temperature-responsive, light-responsive, and MeJA-responsive processes, respectively.

\section{Tissue-specific expression analysis of MsMADS-box genes in alfalfa}

The expression pattern of the MsMADA-box genes in different tissues can infer the role in the process of tissue development of alfalfa. Genome-wide transcriptome data were used to explore the expression profiles of MADS-box genes in different tissues during the development of alfalfa, which were downloaded from the CADL-Gene Expression Atlas (https://www. alfalfatoolbox.org) provided by the Noble Research Institute [64]. The expression data of six tissues, including leaves, flowers, pre-elongated stems, elongated stems, roots, and nodules, were analyzed. TBtools software was used to cluster these expression data and generate a heatmap.

\section{Expression analysis of MsMADS-box genes under abiotic stresses}

In previous studies, to acquire additional genetic information on alfalfa under abiotic stresses, four RNA-Seq projects of alfalfa under cold (SRR7091780SRR7091794), drought, salt and ABA treatments (SRR7160313-SRR7160357) were performed. In this study, to realize the roles of MsMADS-box genes in response to abiotic stresses, the nucleotide sequences of all MsMADS-box genes were used as query sequences for local nucleotide blast (BLASTN) against these four transcriptome datasets [65]. Subsequently, TBtools software was applied to calculate the gene expression values and draw a heatmap of MsMADS-box genes under abiotic stresses.

\section{Plant materials and stress treatments}

The plant material used in this experiment was cultivated 'XinJiangDaYe' alfalfa. All experimental materials were obtained using a hydroponic method in this study. First, we selected seeds that were full and uniform in shape. After alfalfa seeds were surface sterilized, they were regularly placed onto two layers of filter paper moistened with distilled water in square Petri dishes at $22{ }^{\circ} \mathrm{C}$. After germination for 5 days, seedlings with the same taproot length were uniformly transferred into a hydroponic pot containing $1 / 2$ MS nutrient solution $(\mathrm{pH}=5.8)$ that was changed every two days. Subsequently, the seedlings were cultivated under the following conditions: $16 \mathrm{~h}$ light $/ 8 \mathrm{~h}$ dark cycle, relative humidity of $80 \%$, and a temperature of $22{ }^{\circ} \mathrm{C}$. The alfalfa seedlings were subjected to different stress treatments when the third leaf appeared (approximately 10 days after germination). For the cold treatment, alfalfa seedlings were transferred to an artificial climate chamber at $4{ }^{\circ} \mathrm{C}$ for $0,2,6,24$, and $48 \mathrm{~h}$, and then whole seedlings of alfalfa were collected. For exogenous ABA treatment, $10 \mu \mathrm{M}$ ABA dissolved in $1 / 2 \mathrm{MS}$ nutrient solution was used. The root tips of alfalfa seedlings were collected at $0,1,3$ and $12 \mathrm{~h}$ after ABA treatment. To simulate drought and salt stress conditions, individual 
alfalfa seedlings were immersed in 1/2 MS nutrient solution containing $400 \mathrm{mM}$ mannitol and $250 \mathrm{mM}$ $\mathrm{NaCl}$, respectively. Subsequently, the root tips of the alfalfa seedlings were harvested after drought and salt stress conditions at different time points $(0,1,3,6$, 12 , and $24 \mathrm{~h}$ and 1 and $12 \mathrm{~h}$ after stress removal). In order to be consistent with the experimental materials used in the previous transcriptome sequencing in our laboratory, total of six whole seedlings were harvested and mixed into frozen tubes at each time point for cold treatment, and six root tips were collected in the same method for ABA, drought, and salt treatment. All samples were quickly frozen in liquid nitrogen and stored at $-80{ }^{\circ} \mathrm{C}$ until use.

\section{Quantitative real-time PCR analysis}

Eight MsMADS-box genes were selected for qRT-PCR experiments to validate the RNA-Seq data. The TRIzol method (Sangon Biotech, Shanghai, China) was used to isolate the total RNA of the whole seedlings under cold treatment $(0,2,6,24$, and $48 \mathrm{~h})$ and root tips under drought and salt treatments $(0,1,3,6,12$, and $24 \mathrm{~h}$ and 1 and $12 \mathrm{~h}$ after stress removal) and ABA treatments $(0$, 1, 3 and 12 h). Subsequently, a NanoDrop ND1000 spectrophotometer (Thermo Scientific, Waltham, MA, USA) was applied to determine the concentration of each sample. The first-strand cDNA of each sample was synthesized using a FastKing RT Kit (Tiangen Biotech, Beijing, China) according to the manufacturer's instructions. The expression patterns of MsMADS-box genes were explored by using a CFX96 Real-Time PCR Detection System (Bio-Rad, Los Angeles, CA, USA) with 2xSG Fast qPCR Master Mix (Sangon Biotech, Shanghai, China). The total reaction system was $10 \mu \mathrm{L}$, containing $5 \mu \mathrm{L}$ of 2xSG Fast qPCR Master Mix, $2.6 \mu \mathrm{L}$ of $\mathrm{ddH}_{2} \mathrm{O}, 1 \mu \mathrm{L}$ of DAF buffer, $1 \mu \mathrm{L}$ of cDNA, $0.2 \mu \mathrm{L}$ of upstream primer, and $0.2 \mu \mathrm{L}$ of downstream primer. The qRT-PCR protocol was as follows: $95{ }^{\circ} \mathrm{C}$ for $30 \mathrm{~s}$, followed by 40 cycles of $95{ }^{\circ} \mathrm{C}$ for $5 \mathrm{~s}$ and $60{ }^{\circ} \mathrm{C}$ for 30 s. Primer Premier 6 software (Premier Biosoft International, Palo Alto, CA, USA) was applied to design the specific primers for qRT-PCR, and the primer sequences are listed in Additional file 1: Table S8. The Medicago actin gene was used as the reference gene. Three biological replicates of each of the samples for qRT-PCR analysis were analyzed. The relative quantification method $\left(2^{-\Delta \Delta C T}\right)$ was used to calculate the relative expression levels of MsMADS-box genes [66]. In addition, it is known that the expression of few genes exhibits circadian rhythm, which oscillates a rhythm signal with a $24 \mathrm{~h}$ cycle. Therefore, we examined the expression pattern of eight MsMADS-box genes over time under unstressed conditions to verify the effect of circadian rhythm. For example, in the case of cold treatment, we investigated eight MsMADS-box genes expression levels of $0,2,6,24$, and $48 \mathrm{~h}$ in plants grown without cold treatment. For drought and salt treatments, we explored these genes expression of $0,1,3,6,12$, and $24 \mathrm{~h}$ and removal 1 and $12 \mathrm{~h}$ in plants grown in water. As for ABA treatment, we surveyed the gene expression of $0,1,3$ and $12 \mathrm{~h}$ in plant grown under without treatment conditions.

\section{Abbreviations}

TFs: Transcription factors; Chr: Chromosome; 1/2 MS: Half-strength murashige and skoog; ABA: Abscisic acid; FPKM: Fragments Per Kilobase of transcript per Million mapped reads

\section{Supplementary Information}

The online version contains supplementary material available at https://doi. org/10.1186/s12864-021-07911-9.

Additional file 1: Table S1. List of the MADS-bBox sequences in Alfalfa. Table S2. Protein property of MsMADS-box proteins. Table S3. Gene ontology (GO) annotation results of 120 MsMADS-box genes. Table S4. The structural features of motif 1-20. Table S5. Expression (FPKM) of MsMADS-box genes in different tissues. Table S6. Expression (FPKM) of MSMADS-box genes in response to cold, ABA, drought, and salt treatment in alfalfa. Table S7. Ct values of eight MSMADS-box genes in response to cold, drought, salt, and ABA treatment in alfalfa. Table S8. Sequences of primers used in GRT-PCR.

Additional file 2: Figure S1. Phylogenetic tree of Type II MADSbox genes in alfalfa and Arabidopsis constructed using the NJ method in MEGA-X. Group II is divided into 13 subgroups represented by different colors, and alfalfa and Arabidopsis MADS-box genes are indicated by blue stars and red triangles, respectively. Figure S2. Gene structure analysis of MsMADS-box genes in alfalfa. Black lines represent the introns, and green blocks represent the exons. Figure S3. Motif analysis of MsMADS-box proteins. Each motif is represented by boxes of different colors for motifs 01 to 20. Figure S4. Cis-regulatory elements analysis of the promoter regions of MADS-box genes of alfalfa. The differently colored boxes with numbers indicate the numbers of cis-regulatory elements in the promoter regions of MADS-box genes. Figure S5. Expression levels of 104 MADSbox genes in response to cold treatment in alfalfa. Heat map showing the changes in the relative expression of these genes at 0 (CK), 2, 6, 24, and $48 \mathrm{~h}$ under cold treatment at $4{ }^{\circ} \mathrm{C}$ in the whole seedling. Groups $\mathrm{A}$ to $\mathrm{F}$ exhibited six expression patterns of the tested MADS-box genes under cold treatment. Figure S6. Expression levels of 104 MADS-box genes in alfalfa under ABA, drought, and salt treatments. Heatmap showing the relative expression levels of total MADS-box genes at different time points after ABA treatment $(0,1,3$ and $12 \mathrm{~h})$, drought treatment $(0$, $1,3,6,12$, and $24 \mathrm{~h} 1 \mathrm{~h}$ and $12 \mathrm{~h}$ after removal), and salt treatment $(0,1$, $3,6,12$, and $24 \mathrm{~h}$ and $1 \mathrm{~h}$ and $12 \mathrm{~h}$ after removal) in the root tip; "CK" represents $0 \mathrm{~h}$. Groups A to I show nine expression patterns of MADSbox genes under the three treatments. Figure S7. Gene expression analysis of eight MSMADS-box genes without cold treatment for 0, 2, 6, 24 and $48 \mathrm{~h}$ using QRT-PCR. The error bars indicate the standard errors of three biological replicates. Asterisks represent significant differences compared with "CK", and $P<0.05\left(^{*}\right)$ was considered highly significant. Figure S8. Gene expression analysis of eight MSMADS-box genes without drought and salt treatment for $0,1,3,6,12$, and $24 \mathrm{~h}$ and $1 \mathrm{~h}$ and $12 \mathrm{~h}$ after removal using qRT-PCR. The error bars indicate the standard errors of three biological replicates. Asterisks represent significant differences compared with "CK", and $P<0.05\left(^{*}\right)$ was considered highly significant. Figure S9. Gene expression analysis of eight MsMADS-box genes without $A B A$ treatment for $0,1,3$, and 12 h using qRT-PCR. The error bars indicate the standard errors of three biological replicates. Asterisks represent significant differences compared with " $\mathrm{CK}^{\prime}$ ", and $P<0.05\left(^{*}\right)$ was considered highly significant. 


\section{Authors' contributions}

ZPL and XMD conceived and designed the experiment. XMD, HD, WXM, and QZ performed the experiments. XMD and HD analyzed all the data. XMD wrote he manuscript. ZPL revised the manuscript. All of the authors read and approved the final manuscript.

\section{Funding}

This research was supported by the National Natural Science Foundation of China (31722055) and the Key Science and Technology Foundation of Gansu Province (19ZD2NA002).

\section{Availability of data and materials}

The draft genome data of autotetraploid cultivated alfalfa was obtained from https://figshare.com/projects/whole_genome_sequencing_and_assembly_ of_Medicago_sativa/66380. The Arabidopsis and rice MADS-box protein sequences were downloaded from The Arabidopsis Information Resource (TAIR9) (www.arabidopsis.org) and the Rice Genome Annotation Project (http://rice.plantbiology.msu.edu/), respectively. The MADS-box protein sequences of Medicago truncatula were obtained from the LIS-Legume Information System (https://legumeinfo.org/home). Genome-wide transcriptome data of different alfalfa tissues were acquired from the CADL-Gene Expression Atlas (https://www.alfalfatoolbox.org). All transcriptome sequencing data used in this study are available in NCBI SRA (https://www.ncbi.nlm.nih.gov/ sra/): SRR7091780-SRR7091794 (cold treatment) and SRR7160313-SRR7160357 (ABA, drought and salt treatments).

\section{Declarations}

\section{Ethics approval and consent to participate}

We conducted the experimental research on cultivated alfalfa in accordance with the IUCN Policy Statement on Research Involving Species at Risk of Extinction and the Convention on the Trade in Endangered Species of Wild Fauna and Flora. Alfalfa seeds of XinJiangDaYe was provided by the National Livestock Husbandry Station, Ministry of Agriculture and Rural Affairs of The People's Republic of China.

\section{Consent for publication}

Not applicable.

\section{Competing interests}

The authors declare that they have no competing interests.

Received: 6 April 2021 Accepted: 23 July 2021

Published online: 07 August 2021

\section{References}

1. Messenguy F, Dubois E. Role of MADS box proteins and their cofactors in combinatorial control of gene expression and cell development. Gene. 2003;316:1-21

2. Passmore S, Maine GT, Elble R, Christ C, Tye BK. Saccharomyces cerevisiae protein involved in plasmid maintenance is necessary for mating of MAT alpha cells. J Mol Biol. 1988;204(3):593-606.

3. Yanofsky MF, Ma H, Bowman JL, Drews GN, Feldmann KA, Meyerowitz EM. The protein encoded by the Arabidopsis homeotic gene agamous resembles transcription factors. Nature. 1990;346(6279):35-39.

4. Sommer H, Beltrán JP, Huijser P, Pape H, Lönnig WE, Saedler H, SchwarzSommer Z. Deficiens, a homeotic gene involved in the control of flower morphogenesis in Antirrhinum majus: the protein shows homology to transcription factors. EMBO J. 1990;9(3):605-13.

5. Norman C, Runswick M, Pollock R, Treisman R. Isolation and properties of CDNA clones encoding SRF, a transcription factor that binds to the c-fos serum response element. Cell. 1988;55(6):989-1003.

6. Alvarez-Buylla ER, Pelaz S, Liljegren SJ, Gold SE, Burgeff C, Ditta GS, de Pouplana LR, Martnez-Castilla L, Yanofsky MF. An ancestral MADS-box gene duplication occurred before the divergence of plants and animals. Proc Natl Acad Sci USA. 2000;97(10):5328-33.

7. Smaczniak C, Immink RG, Angenent GC, Kaufmann K. Developmental and evolutionary diversity of plant MADS-domain factors: insights from recent studies. Development. 2012;139(17):3081-3098.
8. Henschel K, Kofuji R, Hasebe M, Saedler H, Münster T, Theissen G. Two ancient classes of MIKC-type MADS-box genes are present in the moss Physcomitrella patens. Mol Biol Evol. 2002;19(6):801-814.

9. Díaz-Riquelme J, Lijavetzky D, Martínez-Zapater JM, Carmona MJ. Genomewide analysis of MIKC -type MADS box genes in grapevine. Plant Physiol. 2009;149(1):354-369.

10. Theissen G, Kim JT, Saedler H. Classification and phylogeny of the MADSbox multigene family suggest defined roles of MADS-box gene subfamilies in the morphological evolution of eukaryotes. J Mol Evol. 1996;43(5):484516.

11. Theissen G, Becker A, Di Rosa A, Kanno A, Kim JT, Münster T, Winter KU, Saedler H. A short history of MADS-box genes in plants. Plant Mol Biol. 2000:42(1):115-149.

12. Michaels SD, Ditta G, Gustafson-Brown C, Pelaz S, Yanofsky M, Amasino RM. AGL24 acts as a promoter of flowering in Arabidopsis and is positively regulated by vernalization. Plant J. 2003;33(5):867-874.

13. Dong TT, Hu ZL, Deng L, Wang Y, Zhu MK, Zhang JL, Chen GP. A tomato MADS-box transcription factor, SIMADS1, acts as a negative regulator of fruit ripening. Plant Physiol. 2013;163(2):1026-1036.

14. Lozano R, Angosto T, Gómez P, Payán C, Capel J, Huijser P, Salinas J, Martinez-Zapater JM. Tomato flower abnormalities induced by low temperatures are associated with changes of expression of MADS-Box genes. Plant Physiol. 1998;117(1):91-100.

15. Tardif G, Kane NA, Adam H, Labrie L, Major G, Gulick P, Sarhan F, Laliberté JF. Interaction network of proteins associated with abiotic stress response and development in wheat. Plant Mol Biol. 2007;63(5):703-718.

16. Lee S, Woo YM, Ryu SI, Shin YD, Kim WT, Park KY, Lee IJ, An G. Further characterization of a rice AGL12 group MADS-box gene, OsMADS26. Plant Physiol. 2008;147(1):156-168.

17. Khong GN, Pati PK, Richaud F, Parizot B, Bidzinski P, Mai CD, Bès M, Bourrié I, Meynard D, Beeckman T, Selvaraj MG, Manabu I, Genga AM, Brugidou C, Nang Do V, Guiderdoni E, Morel JB, Gantet P. OsMADS26 Negatively regulates resistance to pathogens and drought tolerance in rice. Plant Physiol. 2015;169(4):2935-49.

18. Agarwal P, Khurana P. Overexpression of TaMADS from wheat promotes flowering by upregulating expression of floral promoters and provides protection against thermal stress. Plant Gene. 2019;17:100168.

19. Guo XH, Chen GP, Cui BL, Gao Q, Guo JE, Li AZ, Zhang LC, Hu ZL. Solanum lycopersicum agamous-like MADS-box protein AGL15-like gene, SIMBP11, confers salt stress tolerance. Mol Breeding. 2016;36(9):125.

20. Liu WX, Xiong CH, Yan LF, Zhang ZS, Ma LC, Wang YR, Liu YJ, Liu ZP. Transcriptome analyses reveal candidate genes potentially involved in Al stress response in alfalfa. Front Plant Sci. 2017;8:26.

21. Chen HT, Zeng $Y$, Yang $Y Z$, Huang LL, Tang BL, Zhang H, Hao F, Liu W, $L i$ YH, Liu YB, Zhang XS, Zhang R, Zhang YS, Li YX, Wang K, He H, Wang ZK, Fan GY, Yang H, Bao AK, Shang ZH, Chen JH, Wang W, Qiu Q. Allele-aware chromosome-level genome assembly and efficient transgene-free genome editing for the autotetraploid cultivated alfalfa. Nat Commun. 2020;11:2494.

22. Bao AK, Du BQ, Touil LL, Kang P, Wang QL, Wang SM. Co-expression of tonoplast Cation/ $/\left(^{+}\right)$antiporter and $\left.\mathrm{H}^{+}\right)$-pyrophosphatase from xerophyte Zygophyllum xanthoxylum improves alfalfa plant growth under salinity, drought and field conditions. Plant Biotechnol J. 2016; 14(3):964-975.

23. Ashrafi E, Razmjoo J, Zahedi M, Pessarakli M. Selecting alfalfa cultivars for salt tolerance based on some physiochemical traits. Agron J. 2014;106(5): 1758-1764.

24. Shen C, Du HL, Chen Z, Lu HW, Zhu FG, Chen H, Meng XZ, Liu QW, Liu P, Zheng $L H$, Li XX, Dong $L$, Liang CZ, Wang T. The chromosome-level genome sequence of the autotetraploid alfalfa and resequencing of core germplasms provide genomic resources for alfalfa research. Mol Plant. 2020; 13(9):1250-1261.

25. Genome-wide analysis of the MADS-box gene family in polyploid cotton (Gossypium hirsutum) and in its diploid parental species (Gossypium arboreum and Gossypium raimondii). Plant Physiol Bioch. 2018;127:169-184.

26. Arora R, Agarwal P, Ray S, Singh AK, Singh VP, Tyagi AK, et al. MADS-box gene family in rice: genome-wide identification, organization and expression profiling during reproductive development and stress. BMC Genomics. 2007:8:242.

27. Wang RZ, Ming ML, Li JM, Shi DQ, Qiao X, Li LT, Zhang SL, Wu J. Genomewide identification of the MADS-box transcription factor family in pear 
(Pyrus bretschneideri) reveals evolution and functional divergence. PeerJ. 2017;5:e3776.

28. Parenicová L, de Folter S, Kieffer M, Horner DS, Favalli C, Busscher J, Cook HE, Ingram RM, Kater MM, Davies B, Angenent GC, Colombo L. Molecular and phylogenetic analyses of the complete MADS-box transcription factor family in Arabidopsis: new openings to the MADS world. Plant Cell. 2003; 15(7):1538-1551.

29. Zhang ZB, Li HY, Zhang DF, Liu YH, Fu J, Shi YS, Song YC, Wang TY, Li Y Characterization and expression analysis of six MADS-box genes in maize (Zea mays L.). J Plant Physiol. 2012;169(8):797-806.

30. Saha G, Park JI, Jung HJ, Ahmed NU, Kayum MA, Chung MY, Hur Y, Cho YG, Watanabe M, Nou IS. Genome-wide identification and characterization of MADS-box family genes related to organ development and stress resistance in Brassica rapa. BMC Genomics. 2015;16(1):1-21.

31. Zhou Q, Che TL, Wang YR, Liu ZP. The development of 204 novel EST-SSRs and their use for genetic diversity analyses in cultivated alfalfa. Biochem Syst Ecol. 2014;57:227-230.

32. Luo D, Wu YG, Liu J, Zhou Q, Liu WX, Wang YR. Yang QC, Wang ZY, Liu ZP. Comparative transcriptomic and physiological analyses of Medicago sativa $\mathrm{L}$. indicates that multiple regulatory networks are activated during continuous ABA treatment. Int J Mol Sci. 2018;20(1):47.

33. Luo D, Zhou Q, Wu YG, Chai XT, Liu WX, Wang YR, Yang QC, Wang ZY, Liu ZP. Full-length transcript sequencing and comparative transcriptomic analysis to evaluate the contribution of osmotic and ionic stress components towards salinity tolerance in the roots of cultivated alfalfa (Medicago sativa L.). BMC Plant Biol. 2019;19:32.

34. Liu JY, Fu XD, Dong YW, Lu J, Ren M, Zhou NN, Wang CQ. MIKC ${ }^{C}$-type MADS-box genes in Rosa chinensis: the remarkable expansion of $A B C D E$ model genes and their roles in floral organogenesis. Hortic Res. 2018; 5(1):25.

35. Chen RG, Ma JH, Luo D, Hou XM, Ma F, Zhang YM, Meng YC, Zhang HF, Guo WL. CaMADS, a MADS-box transcription factor from pepper, plays an important role in the response to cold, salt, and osmotic stress. Plant Sci. 2019;280:164-174.

36. Ning K, Han YY, Chen ZJ, Luo C, Wang SL, Zhang WJ, Li L, Zhang XL, Fan SX, Wang Q. Genome-wide analysis of MADS-box family genes during flower development in lettuce. Plant Cell Environ. 2019;42(6): 1868-1881.

37. Tang W, Tu YY, Cheng XJ, Zhang LL, Meng HL, Zhao X, Zhang W, He B. Genome-wide identification and expression profile of the MADS-box gene family in Erigeron breviscapus. PLoS One. 2019;14(12):e0226599.

38. Zhang $Y T$, Tang DQ, Lin XC, Ding MQ, Tong ZK. Genome-wide identification of MADS-box family genes in moso bamboo (Phyllostachys edulis) and a functional analysis of PeMADS5 in flowering. BMC Plant Biol. 2018;18(1):176

39. Wang YS, Zhang JL, Hu ZL, Guo XH, Tian SB, Chen GP. Genome-Wide Analysis of the MADS-Box Transcription Factor Family in Solanum lycopersicum. Int J Mol Sci. 2019;20(12):2961.

40. Yang SP, Gao JM, Wang LH, Sun XM, Xu PP, Zhang LW, Zhong QW. Functional annotation and identification of MADS-box transcription factors related to tuber dormancy in Helianthus tuberosus L. 3 Biotech. 2019;9(10);1-13.

41. Honma T, Goto K. Complexes of MADS-box proteins are sufficient to convert leaves into floral organs. Nature. 2001;409(6819):525-529.

42. Nesi N, Debeaujon I, Jond C, Stewart AJ, Jenkins Gl, Caboche M, Lepiniec L. The TRANSPARENT TESTA16 encodes the ARABIDOPSIS BSISTER MADS domain protein and is required for proper development and pigmentation of the seed coat. Plant Cell. 2002;14(10):2463-79.

43. Ren ZY, Yu DQ, Yang ZE, Li CF, Qanmber G, Li Y, Li J, Liu Z, Lu LL, Wang LL, Zhang H, Chen QJ, Li FG, Yang ZR. Genome-wide identification of the MIKC Type MADS-box gene family in Gossypium hirsutum L. unravels their roles in flowering. Front Plant Sci. 2017;8:384-400.

44. Liu X, Sun ZC, Dong W, Wang ZJ, Zhang LS. Expansion and functional divergence of the SHORT VEGETATIVE PHASE (SVP) genes in Eudicots. Genome Biol Evol. 2018;10(11):3026-3037.

45. Zhou Q, Jia CL, Ma WX, Cui Y, Jin XY, Luo D, Min XY, Liu ZP. MYB transcription factors in alfalfa (Medicago sativa): Genome-wide identification and expression analysis under abiotic stresses. Peer J. 2019;7(49):e7714.

46. Mao P, Jin XY, Bao QY, Mei C, Zhou Q, Min XY, Liu ZP. WRKY transcription factors in Medicago sativa L.: Genome-wide identification and expression analysis under abiotic stress. DNA Cell Biol. 2020;39(12):1-14.
47. Cao B, Cui Y, Lou KK, Luo D, Liu ZP, Zhou Q. Genome-wide identification and expression analysis of the Dof gene family in Medicago sativa $\mathrm{L}$. under various abiotic stresses. DNA Cell Biol. 2020;39(11):1-14.

48. Yamaquchi-Shinozaki K, Shinozaki K. Transcriptional regulatory networks in cellular responses and tolerance to dehydration and cold stresses. Annu Rev Plant Biol. 2006;57(1):781-803.

49. Tian Y, Dong QL, Ji ZR, Chi FM, Cong PH, Zhou ZS. Genome-wide identification and analysis of the MADS-box gene family in apple. Gene. 2015:555(2):277-290.

50. Wells CE, Vendramin E, Jimenez Tarodo S, Verde I, Bielenberg DG. A genome-wide analysis of MADS-box genes in peach [Prunus persica (L.) Batsch]. BMC Plant Biol. 2015;15(1):41-55.

51. Zhao HB, Jia HM, Wang Y, Wang GY, Zhou CC, Jia HJ, Gao ZS. Genome-wide identification and analysis of the MADS-box gene family and its potential role in fruit development and ripening in red bayberry (Morella rubra). Gene. 2019;717:144045.

52. Tadege M, Sheldon CC, Helliwell CA, Upadhyaya NM, Dennis ES, Peacock WJ. Reciprocal control of flowering time by $\mathrm{OSSOC1}$ in transgenic Arabidopsis and by FLC in transgenic rice. Plant Biotechnol J. 2003;1(5):361-369.

53. Shitsukawa N, Ikari C, Mitsuya T, Sakiyama T, Ishikawa A, Takumi S, Murai K. Wheat SOC1 functions independently of WAPINRN1, an integrator of vernalization and photoperiod flowering promotion pathways. Physiol Plant. 2007;130(4):627-36.

54. Zhong XF, Dai X, Xu JH, Wu HY, Liu B, Li HY. Cloning and expression analysis of GmGAL1, SOC1 homolog gene in soybean. Mol Biol Rep. 2012; 39(6):6967-6974.

55. Bai G, Yang DH, Cao PJ, Yao H, Zhang YH, Chen XJ, Xiao BG, Li F, Wang ZY, Yang J, Xie H. Genome-Wide Identification, Gene structure and expression analysis of the MADS-Box gene family indicate their function in the development of Tobacco (Nicotiana tabacum L.). Int J Mol Sci. 2019;20(20):5043.

56. Kaufmann K, Melzer R, Theissen G. MIKC-type MADS domain proteins: structural modularity, protein interactions and network evolution in land plants. Gene. 2005;347(2):183-198.

57. Jia JT, Zhao PC, Cheng LQ, Yuan GX, Yang WG, Liu S, Chen SY, Qi DM, Liu GS, Li XX. MADS-box family genes in sheepgrass and their involvement in abiotic stress responses. BMC Plant Biol. 2018;18(1):42.

58. Yang F, Xu F, Wang XH, Liao YL, Chen QW, Meng XX. Characterization and functional analysis of a MADS-box transcription factor gene (GbMADS9) from Ginkgo biloba. Sci Hortic. 2016;212:104-114.

59. Cao J, Sun L, Li J, Zhou C, Cheng L, Chen K, Yan B, Qian W, Ma Q, Duan W. A novel three-miRNA signature predicts survival in cholangiocarcinoma based on RNA-seq data. Oncol Rep. 2018;40:1422-34.

60. Zhang T, Chen H, Qi L, Zhang J, Wu R, Zhang Y, Sun Y. Transcript profiling identifies early response genes against FMDV infection in PK-15 cells. Viruses. 2018;10(7):364.

61. Zhang XD, Fatima M, Zhou P, Ma Q, Ming R. Analysis of MADS-box genes revealed modified flowering gene network and diurnal expression in pineapple. BMC Genomics. 2020;21:8.

62. Gotz S, Garcia-Gomez JM, Terol J, Williams TD, Nagaraj SH, Nueda MJ, Robles M, Talon M, Dopazo J, Conesa A. High-throughput functional annotation and data mining with the Blast2GO suite. Nucleic Acids Res. 2008:36(10):3420-35.

63. Chen CJ, Chen H, Zhang Y, Thomas HR, Frank MH, He YH, Xia R. TBtools: an integrative toolkit developed for interactive analyses of big biological data. Mol Plant. 2020;13(8):1194-1202.

64. O'Rourke JA, Fu F, Bucciarelli B, Yang SS, Samac DA, Lamb JAFS, Monteros MJ, Graham MA, Gronwald JW, Krom N, Li J, Dai XB, Zhao PX, Vance CP. The Medicago sativa gene index 1.2: a web-accessible gene expression atlas for investigating expression differences between Medicago sativa subspecies. BMC Genomics. 2015;16(1):502-518.

65. Camacho C, Coulouris G, Avagyan V, Ma N, Papadopoulos J, Bealer K, Madden TL. BLAST+: architecture and applications. BMC Bioinformatics. 2009;10:421

66. Livak KJ, Schmittgen TD. Analysis of relative gene expression data using real-time quantitative PCR and the $2^{-\Delta \Delta C T}$ method. Methods. 2001;25(4): 402-408.

\section{Publisher's Note}

Springer Nature remains neutral with regard to jurisdictional claims in published maps and institutional affiliations. 